\title{
Rethinking Mobile Interfaces for Older Adults
}

\author{
Neil Charness \\ Florida State University \\ Florida, USA \\ charness@psy.fsu.edu

\section{Mark Dunlop} \\ Strathclyde University, UK \\ mark.dunlop@strath.ac.uk

\section{Cosmin Munteanu} \\ University of Toronto \\ Mississauga, Canada \\ cosmin.munteanu@utoronto.ca \\ Emma Nicol \\ Strathclyde University, UK \\ emma.nicol@strath.ac.uk

\section{Antti Oulasvirta \\ Aalto University, Finland \\ antti.oulasvirta@aalto.fi}

\section{Xiangshi Ren} \\ Kochi University of Technology \\ Kochi, Japan \\ ren.xiangshi@kochi-tech.ac.jp

\section{Sayan Sarcar} \\ Kochi University of Technology \\ Kochi, Japan \\ sayan.sarcar@kochi-tech.ac.jp \\ Chaklam Silpasuwancha \\ Kochi University of Technology \\ Kochi, Japan \\ chaklam@kochi-tech.ac.jp
}

Permission to make digital or hard copies of part or all of this work for personal or classroom use is granted without fee provided that copies are not made or distributed for profit or commercial advantage and that copies bear this notice and the full citation on the first page. Copyrights for third-party components of this work must be honored. For all other uses, contact the Owner/Author.

Copyright is held by the owner/author(s).

CHI'16 Extended Abstracts, May 07-12, 2016, San Jose, CA, USA ACM $978-1-4503-4082-3 / 16 / 05$

http://dx.doi.org/10.1145/2851581.288643

\begin{abstract}
This SIG advances the study of mobile user interfaces for the aging population. The topic is timely, as the mobile device has become the most widely used computer terminal and at the same time the number of older people will soon exceed the number of children worldwide. However, most HCI research addresses younger adults and has had little impact on older adults. Some design trends, like the mantra "smaller is smarter", contradict the needs of older users. Developments like this may diminish their ability to access information and participate in society. This can lead to further isolation (social and physical) of older adults and increased widening of the digital divide. This SIG aims to discuss mobile interfaces for older adults. The SIG has three goals: (i) to map the state-of-art, (ii) to build a community gathering experts from related areas, and (iii) to raise awareness within the SIGCHI community. The SIG will be open to all at $\mathrm{CHI}$.
\end{abstract}

\section{Author Keywords}

Older adults; Mobile interface design; Cognitive models; Empirical studies; Accessibility; Cognitive psychology; Gerontology; Gerontechnology 

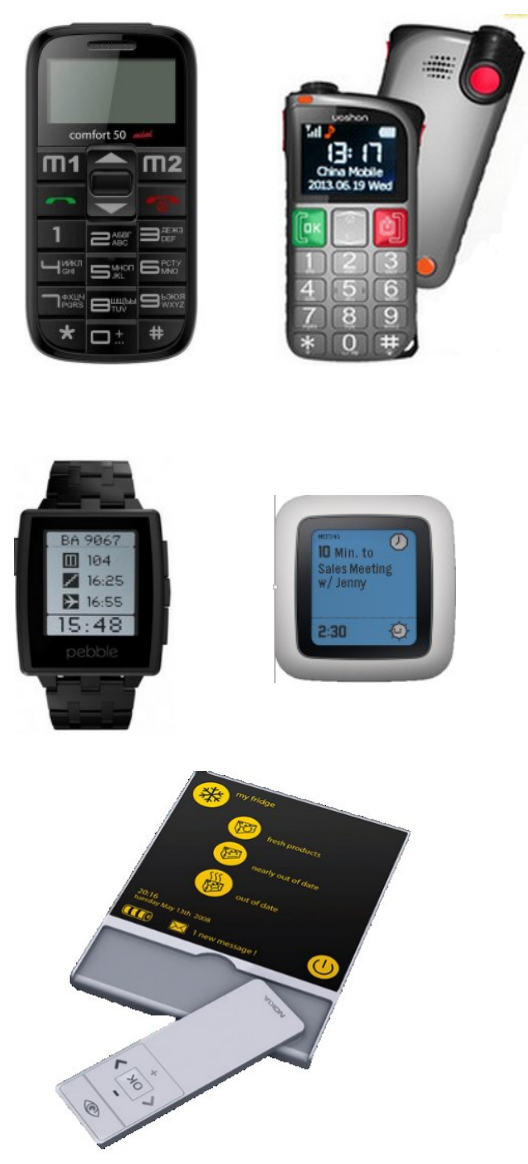

Figure 1: Most interfaces for older adults simply dumb down the

functionality of the mobile phones and do not allow access to the full range of functionality.

\section{ACM Classification Keywords}

H.5.2. Information interfaces and presentation: User Interface - Input devices and strategies

\section{Introduction}

Both more developed and less developed nations are experiencing rapid ageing of their populations with those age $65+$ years expected to become $27 \%$ and $15 \%$ of these nations, respectively, by $2050[4,6]$. Although issues related to older adults are receiving substantial attention in other areas of research, the HCI community might contribute more.

Aging is associated with a multitude of biological, cognitive, and social changes that impact the use of technology [5]. For mobile devices in particular, these can seriously hamper usability, for example through reduced visual acuity and less accurate fine motor controls that affect almost everyone as we age. However, age also brings new opportunities that well designed mobile apps could support: for example increasing spare time, strengthening family connections, and new learning/travel opportunities. The digital revolution has not adequately considered the needs of the ageing population. Although older adults constitute an increasing segment of the demographics, the majority of research on $\mathrm{HCI}$ focusses almost exclusively on younger adults, a trend reflected in industrial developments and in evaluation studies of mobiles. As a consequence, older adults may be losing the possible benefits and opportunities from this growing digital era (see Figure 1).

In contrast to the youth focused mainstream of mobile research and development, there is a growing use of mobiles to support older adults with special needs and many of the lessons from this research could have wider implications for age-agnostic design and evaluation.

\section{Focus Areas}

This SIG focuses on mobile devices, perhaps the most challenging but potentially most available platform for the ageing population. We interpret "mobile device" broadly to include current and future forms of mobile computing, including phones, tablets and wearables. Mobile devices' ownership rates for older adults are increasing [3], yet there are few suitable concrete design principles $[1,5]$. Further, evaluating both the usability and the social/personal benefits of seniorcentred mobile interfaces is challenging and not well supported by existing $\mathrm{HCI}$ [7]. By providing easier access to information through mobile devices, older adults can be gain more benefits.

\section{Goals}

This SIG aims to reach three goals.

\section{Building a research repository}

Presently researchers working on this topic are scattered across different fields. The research outcomes, experiences, and practices are not disseminated across the boundaries of these fields. As a consequence, it is difficult for people in different communities to become aware of research progress in the field. A major goal of this SIG is to bring researchers from these fields together to synthesize and collate findings from different disciplines, and create opportunities to explore bridging between several field experts in order to develop efficient, effective, usable, and adoptable mobile technologies and more appropriate methods. The SIG will also be able to discuss critical issues cutting across fields that 
may be hard or nearly impossible to handle within the traditional publication culture.

\section{Community building}

Senior-centred research and development is currently conducted in academic and industry research labs in a rather disjoint manner. As such, this SIG's goal is to link the SIGCHI community with researchers and practitioners across academic disciplines (such as the Cognitive Neuroscience) and industries who are actively working or having interest toward understanding older adults' technology use, specifically mobile applications. For future collaborations, mailing lists and post-chi activity (e.g., workshop) will be established.

\section{Raising Awareness}

Interactive technologies for seniors is a significant market of interest for industries, expected to grow from US $\$ 2$ billion to an estimated US $\$ 30$ billion in the next few years [8]. This is a natural reflection of the size of this user group (16\% of population [9]). Yet interest in $\mathrm{HCI}$ is still relatively small (less than $1 \%$ of all $\mathrm{CHI}$ 2015 accepted submissions across all tracks can be categorized as focused on older adults). This SIG aims to raise awareness of the challenges and research opportunities in this field.

\section{Suggested topics for group discussion}

The group discussion will be structured according to the topics below.

\section{Current issues}

Older adults face many problems while accessing mobile devices. This topic will focus on discussing issues related to human factors, perception, memory, and motor movement of older adults, and how these issues affect the accessibility of senior-based mobile interfaces.

Theories and design

Various theories and design principles have been proposed for older adults. This topic will focus on discussing the state-of-the-art theories and design principles for mobile interfaces of older adults, how effective is the current theories and design principles on improving the accessibility of senior-based mobile interfaces, and identify future research opportunities.

\section{Evaluation methodologies}

Evaluating senior-based user interfaces still face many challenges, particularly on accurately understanding the preferences, habits, and adoption challenges of older adults [10]. For example, there is growing evidence that offspring can be dis-encouraging to older adults and can lead to tensions in study design [11]. This topic will focus on discussing the state-of-the art evaluation methods, to discuss how suitable is the current methods, and identify future research opportunities.

\section{Applications}

Mobile devices open up many new possibilities and opportunities for older adults. This topic will discuss what some potentially useful applications for older adults are. For examples, text-entry methods can enhance the usability of messaging applications. Games and social applications have the potential to improve the wellbeing of older adults. We will conclude with a list of future opportunities for applications. 


\section{Conclusion}

The older adults community is currently very active and regularly makes significant contributions to both the research literature and our society at large. However, our community is scattered across different research fields. In workshops at MobileHCI conference over the past two years organized by two of the committee members, it was attempted to unify the older people researchers scattered across different research fields into an interdisciplinary community centered at $\mathrm{CHI}$. We want to open access our community further by hosting a SIG and pushing the boundaries of the field in a common direction. Trying to establish a set of best practices across our varied communities will position the field to learn from the past and present so that we can march forward together to address the older people interface design challenges of the future.

\section{References}

1. Farah Arab, Yasir Malik, and Bessam Abdulrazak. 2013. Evaluation of phonage: an adapted smartphone interface for elderly. In Proceedings of INTERACT, 547-554.

http://dx.doi.org/10.1007/978-3-642-40498-6_44

2. ComScore 2012. Mobile future in focus, 2012 , Retrieved 16 January 2015 from

https://www.comscore.com/Insights/Press-

Releases/2012/2/comScore-Releases-the-2012Mobile-Future-in-Focus-Report.

3. Deloitte. The smartphone generation gap: over-55? There's no app for that, 2014. Retrieved 15 January 2015 from

http://www2.deloitte.com/global/en/pages/techno ogy-media-and-telecommunications/articles/tmtpredictions-collection.html

4. Miranda A Farage, Kenneth W Miller, Funmi Ajayi, and Deborah Hutchins. Design principles to accommodate older adults. Global journal of health science. 4, 2 (March 2012).

http://dx.doi.org/ 10.5539/gjhs.v4n2p2

5. Arthur D Fisk, Wendy A. Rogers, Neil Charness, Sara J. Czaja, and Joseph Sharit. 2012. Designing for older adults: Principles and creative human factors approaches. CRC press, FL, USA.

6. Query $9 / 22 / 15$ to

http://www.census.gov/population/international/da ta/idb/region. php? $\mathrm{N}=\% 20$ Results $\% 20 \& \mathrm{~T}=1 \& \mathrm{~A}=$ agg regate $\& R T=0 \& Y=2050 \& R=101,102 \& C=$. Retrieved results 30 September, 2015.

7. Barbara B. Neves, Rachel L. Franz, Cosmin Munteanu, Ronald Baecker, and Mags Ngo. 2015. "My hand doesn't listen to me!": adoption and evaluation of a communication technology for the 'oldest old'. In Proceedings of the ACM SIGCHI Conference on Human Factors in Computing Systems (CHI 2015), 1593-1602. http://doi.acm.org/10.1145/2702123.2702430

8. Laurie M. Orlov. Technology for Aging in Place: 2014 Market Overview. Market Report. Retrieved 31 January 2015 from

http://www.ageinplacetech.com/files/aip/Market Overview 1-20-2014 Combined.pdf

9. Stats Canada Population Estimates, 2014. Retrieved 22 February 2015 from http://www.statcan.gc.ca/dailyquotidien/140926/dq140926b-eng.htm.

10. Emma Nicol et al. Workshop on Designing with Older Adults: Towards a Complete Methodology. In Proceedings of ACM MobileHCI 2015. Retrieved 2 October, 2015 from https://olderadultsmobileinterfaces.wordpress.com/

11. Marilyn R. McGee-Lennon, Maria K Wolters, and Stephen Brewster. 2011. User-centred multimodal reminders for assistive living. In Proceedings of ACM CHI Conference (CHI 2011), 2105-2114. http://doi.acm.org/10.1145/1978942.1979248 